\title{
BMJ Open Prevalence and risk factors of frailty among people in rural areas: a systematic review and meta-analysis
}

\author{
Rui Xu, ${ }^{1}$ Qiufang Li (D) , ${ }^{1}$ Feifei Guo, ${ }^{1}$ Maoni Zhao, ${ }^{2}$ Luyao Zhang ${ }^{1}$
}

To cite: Xu R, Li Q, Guo F, et al. Prevalence and risk factors of frailty among people in rural areas: a systematic review and meta-analysis. BMJ Open 2021;11:e043494. doi:10.1136/ bmjopen-2020-043494

- Prepublication history and additional supplemental material for this paper are available online. To view these files, please visit the journal online (http://dx.doi.org/10.1136/ bmjopen-2020-043494)

Received 12 August 2020 Revised 03 January 2021 Accepted 01 April 2021

\section{Check for updates}

(C) Author(s) (or their employer(s)) 2021. Re-use permitted under CC BY-NC. No commercial re-use. See rights and permissions. Published by BMJ.

${ }^{1}$ School of Nursing and Health of Zhengzhou University, Zhengzhou, China

${ }^{2}$ Henan Provincial People's Hospital, Zhengzhou, China

Correspondence to Professor Qiufang Li; liqiufang@zzu.edu.cn

\section{ABSTRACT}

Objective Older people in rural areas are possibly more frail due to the limited medical resources and lower socioeconomic status. Given the negative healthy outcomes caused by frailty, knowing the epidemiology of frailty in rural areas is of great importance. We tried to synthesise the existing evidences for the prevalence and risk factors of frailty in rural areas.

Design A systematic review and meta-analysis.

Data sources PubMed, Embase, MEDLINE, Cochrane Library, Web of Science and Scopus were used to identify the articles from inception to 30 April 2019.

Eligibility criteria Observational studies providing crosssectional data on the prevalence of frailty in rural elderly were extracted.

Data extraction and synthesis Two independent investigators selected studies, extracted data and assessed the methodological quality of included studies. The pool prevalence of frailty was calculated by the random effects model and the $\mathrm{OR}$ and $95 \% \mathrm{Cl}$ were used to calculate the risk factors.

Results The literature search yielded 2219 articles, of which 23 met the study criteria and were included in this analysis. The pooled prevalence of frailty and pre-frailty were $18 \%\left(95 \% \mathrm{Cl} 15 \%\right.$ to $\left.21 \%, \mathrm{I}^{2}=98.5 \%, \mathrm{p}<0.001\right)$ and $50 \%\left(95 \% \mathrm{Cl} 45 \%\right.$ to $\left.56 \%, \mathrm{l}^{2}=98.4 \%, \mathrm{p}<0.001\right)$, respectively. The pooled frailty prevalence was $15 \%$ for the Fried Phenotype, 18\% for the Frailty Index and $23 \%$ for other criteria. The pooled prevalence of frailty was $17 \%$ for males and $26 \%$ for females. The pooled prevalence of frailty was $17 \%$ in developing countries and $23 \%$ in developed countries. Age, cognitive impairment, depressive symptom, risk of malnutrition, activity of daily living (ADL) disability and poor self-perception of health were associated with frailty. There was no publication bias. Conclusions Frailty influences almost one in five older people in rural areas, and increasing age, cognitive impairment, depressive symptom, risk of malnutrition, ADL disability and poor self-perception of health were all risk factors for frailty. We should be cautious about the research results due to the heterogeneity between studies.

\section{INTRODUCTION}

An ageing population is a common phenomenon experienced by all countries in the world, ${ }^{1}$ which brings considerable challenges for the planning and delivery of healthcare services internationally. The

\section{Strengths and limitations of this study}

In this study, we conducted a comprehensive systematic literature search.

- This study focused on the frailty of older people in rural areas that are easily neglected.

- The data are mainly from Asia and North and South America, and lack of data from Europe.

- The main limitation is the heterogeneity among studies of this meta-analysis.

- Stratified meta-analyses cannot explain all sources of heterogeneity.

most problematic manifestation of population ageing is frailty. ${ }^{2}$ Frailty is an age-related medical syndrome, which is characterised by diminished strength, endurance and reduced physiological function that increases an individual's vulnerability for developing increased dependency and/or death. ${ }^{3}$ Frailty has been proved to be associated with negative healthy outcomes, such as hospitalisation, institutionalisation/dependency and premature mortalities. ${ }^{4}$ Ahmad $^{5}$ found that the transition towards greater frailty states were more likely $(22.9 \%)$ than transition toward lesser frailty states $(19.9 \%)$ during a 12-month follow-up through the survey of 2324 elderly and it proved that frailty was potential reversible and this reversibility made it a cornerstone to delay frailty progression. Pre-frailty is an intermediate state between frailty and robustness, which can predispose to the development of frailty and other adverse health and social care outcomes and it is necessary to identify the state of pre-frailty. ${ }^{6}$

With the continuous expansion of the study population, more and more researches begin to pay attention to the frail elderly in rural areas. From high-income countries to subSaharan Africa, under the guidance of cityoriented development path, the gap between urban and rural areas continues to expand. ${ }^{7}$ The elderly person in the rural context, in addition to the peculiarities of the ageing 
process, ${ }^{8}$ shows a series of environment-related characteristics, such as limited educational resources, limited accessibility of healthcare services and resources, lower socioeconomic status, and all of these potential factors may cause the emergence or advancement of frailty. ${ }^{9} 10$ Many countries have explored the prevalence of frailty in rural elderly and the results are quite different, for example the prevalence of frailty is $43.4 \%$ in Brazil ${ }^{8}$ $15.2 \%$ in Sri Lanka, ${ }^{11} 38.8 \%$ in India, ${ }^{12} 18.8 \%$ in France ${ }^{13}$ and even in the same country, the prevalence of frailty varies greatly due to differences in assessment tools, research environments and so on. A recent meta-analysis on prevalence of frailty including 62 countries across the world reported the prevalence of frailty and pre-frailty were $12 \%$ and $46 \%$, respectively, using the tool of Fried phenotype (FP). ${ }^{14}$ However, the included people were from cities, towns and villages, and the data of rural areas is absent.

Hence, it is necessary to synthesise the existing body of evidence and offer a perspective on the prevalence of frailty in rural areas, which are critically important to developing strategies and disease prevention. The objectives of this systematic review were to synthesise the pooled prevalence and risk factors of frailty in rural areas through conducting a meta-analysis.

\section{METHODS}

\section{Protocol}

This review was conducted according to the MOOSE statement which was for the meta-analysis of observational studies in epidemiology. ${ }^{15}$

\section{Search strategy}

We conducted a comprehensive search of the literature using six electronic databases. PubMed, Embase, MEDLINE, Cochrane Library, Web of Science and Scopus were searched from their dates of inception through 30 April 2020 with languages restricted to English. A combination of title/keyword/abstract and Medical Subject Headings were used and the following key words were used: "frailty", "frail", "frail*", "rural", "village", "countryside" and "rural*". Reference lists of relevant literatures were hand-searched for addition studies. The search strategy in PubMed is available in online supplemental table 1 .

\section{Eligibility criteria \\ Condition}

We considered studies reporting the prevalence (or enough data to compute this estimate) of frailty or prefrailty. The measurement of frailty or pre-frailty was based on the assessment tools used. For example, the FP contained five components (weight loss, exhaustion, weakness, slowness and low physical activity) and subjects who were positive for three or more components were defined as frailty, those with one or two component(s) were defined as pre-frailty. ${ }^{16}$ In the studies where frailty or pre-frailty were not defined using the FP, we considered the definition used by authors.

Context

We considered studies conducted in people living in the rural areas. We found that there is no unified definition of rural areas by reviewing the literature. Some studies think that rural areas are the places with the relatively backward economic development, ${ }^{10}$ while others think that rural areas are far away from cities. ${ }^{5}$ Therefore, we will include studies as long as it clearly points out that it conducts in rural contexts.

\section{Population}

We considered studies conducted in older adults $(\geq 60$ years). Studies that limited the study population to specific population such as lung cancer and kidney disease were excluded.

\section{Study design}

Study designs were observational providing crosssectional data on the prevalence of frailty or pre-frailty. Review, editorial, comment and conference abstract were excluded.

\section{Data extraction}

Two investigators extracted data independently and disagreements were resolved by discussion. Data were recorded in the Microsoft Excel file format from each eligible study including the following variables: first author, year and country of publication, study design, sample size, mean or median age of the population, proportion of female, assessment tools of frailty, prevalence of frailty and pre-frailty and risk factors mentioned. We asked for the missing data by sending emails to the corresponding author of the included articles.

\section{Methodological quality assessment}

All eligible articles were subjected to a quality assessment by two investigators independently through the criterion proposed by Loney $e t a l^{17}$ which was designed to critically assess studies about the prevalence. Each study was assigned a summative quality score ranging from 0 to 8 , which was obtained by scoring a point for each of random sample or whole population, unbiased sampling frame (ie, census data), adequate sample size ( $>300$ subjects), measures were the standard, outcomes measured by unbiased assessors, adequate response rate (70\%), CIs, subgroup analysis and study subjects described. Only studies that scored three or above were deemed eligible for inclusion and studies which met more than four criteria were thought to have adequate quality. ${ }^{18} \mathrm{~A}$ third author resolved quality disagreements.

\section{Statistical analysis}

Heterogeneity among studies was tested using $\chi^{2}$ test and the $\mathrm{I}^{2}$ statistic. Studies were considered to have significant heterogeneity if the $\mathrm{p}$ value was less than 0.1 . The $\mathrm{I}^{2}$ statistic was used to assess the degree of heterogeneity, 
with $\mathrm{I}^{2}$ values of $25 \%, 50 \%$ and $75 \%$ being considered to indicate low, moderate and high heterogeneity, respectively. Random-effects model was used to calculate the pooled prevalence of frailty if significant heterogeneity was present; otherwise a fixed-effects model was used. We tried to explore the potential reasons for heterogeneity by conducting stratified meta-analyses. In stratified meta-analyses, the literature data were divided into subgroups according to frailty criteria, gender and level of development, and pooled estimates of frailty prevalence with $95 \%$ CIs were calculated. The prevalence of frailty and pre-frailty were extracted from all included studies in order to calculate the pooled prevalence and the ORs and associated 95\% CIs were extracted to assess the risk factors of frailty in rural elderly. Begg's test and Egger's test were used to assess publication bias.

Statistical analyses were conducted using Stata SE V.12.0 (Stata Corp, College Station, Texas, USA), and a p value $<0.05$ was considered significant.

\section{Patient and public involvement}

There was no direct patient or public involvement in this study.

\section{RESULTS}

\section{Study process}

The systematic search of the six databases retrieved 2219 articles. After 1345 duplicate studies were excluded, a further 783 studies were excluded through screening the title and abstract. Of the 91 studies left, 68 were excluded from the full-text review due to non-data-based article (eg, editorial, commentary, review, conference abstract) $(\mathrm{n}=15)$, same sample $(\mathrm{n}=11)$, non-English $(\mathrm{n}=7)$, no data of frailty in rural elderly $(n=25)$, sample from a specific population (eg, patients with cancer, disabled individuals) $(n=6)$, one more form of frailty assessment $(n=4)$. Finally, 23 published articles, ${ }^{5-12}$ 19-35 involving a total of 32478 older adults in rural areas, were eligible and included in the meta-analysis (figure 1). Of all the studies included, 17 studies have adequate quality (score $>4$ ). The characteristics of studies were showed in table 1 . One of these studies included data from four countries. ${ }^{35}$

\section{Prevalence of frailty and pre-frailty}

The prevalence of frailty and pre-frailty in included studies range from $5.4 \%$ to $43.4 \%,{ }^{835}$ and from $23 \%$ to $67.8 \%,{ }^{22} 23$ respectively. Meta-analysis showed the pooled prevalence of frailty $18 \%$ (95\% CI $15 \%$ to $21 \%, \mathrm{I}^{2}=98.5 \%$, $\mathrm{p}<0.001)$ in rural elderly, with the pooled prevalence of pre-frailty of $50 \%\left(95 \%\right.$ CI $45 \%$ to $56 \%, \mathrm{I}^{2}=98.4 \%$, $\mathrm{p}<0.001$ ) based on a random-effects model (figures 2 and 3). Heterogeneity statistics $\left(\chi^{2}\right.$ test $=1644.51 ; p<0.001$; $\mathrm{I}^{2}=98.5 \%$ ) indicated significant variability among studies. According to the results of Begg's test $(\operatorname{Pr}=0.659>0.05)$ and Egger's test $(\mathrm{p}=0.059>0.05)$, there was no evidence of publication bias.

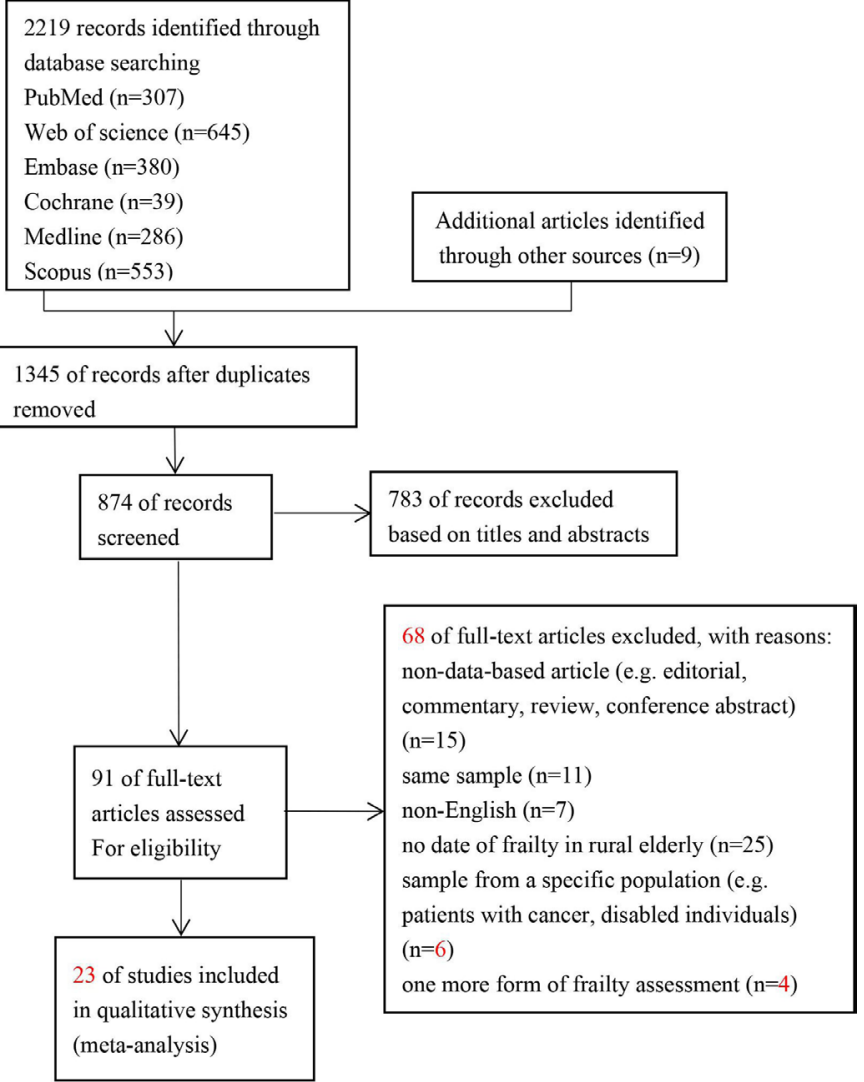

Figure 1 Flow chart of systematic review.

\section{Stratified prevalence of frailty according to frailty criteria, gender and level of development}

The pooled estimates of frailty prevalence based on the FP, FI and other criteria were $15 \%, 18 \%$ and $32 \%$, respectively. The estimated pooled prevalence of frailty was $26 \%$ in females and $17 \%$ in males. The estimated pooled prevalence of frailty was $17 \%$ in developing countries and $23 \%$ in developed countries. Results of subgroup analyses are shown in table 2 .

\section{Risk factors}

We identified six potential risk factors including age, cognitive impairment, depressive symptom, risk of malnutrition, activity of daily living (ADL) disability and poor self-perception of health, which were associated with frailty in rural elderly for the pooled analysis (table 3 ).

\section{DISCUSSION}

Based on 23 studies involving a total of 32478 participants living in rural areas, the estimated pooled prevalence of frailty and pre-frailty of older people in rural areas are $18 \%$ and $50 \%$, respectively. However, this result has to be cautiously interpreted because of the substantial heterogeneity between studies. When assessing potential risk factors associated with frailty in rural elderly, six factors including increasing age, cognitive impairment, depressive symptom, risk of malnutrition, ADL disability and poor self-perception of health were associated with frailty. 
$\frac{2}{3}$

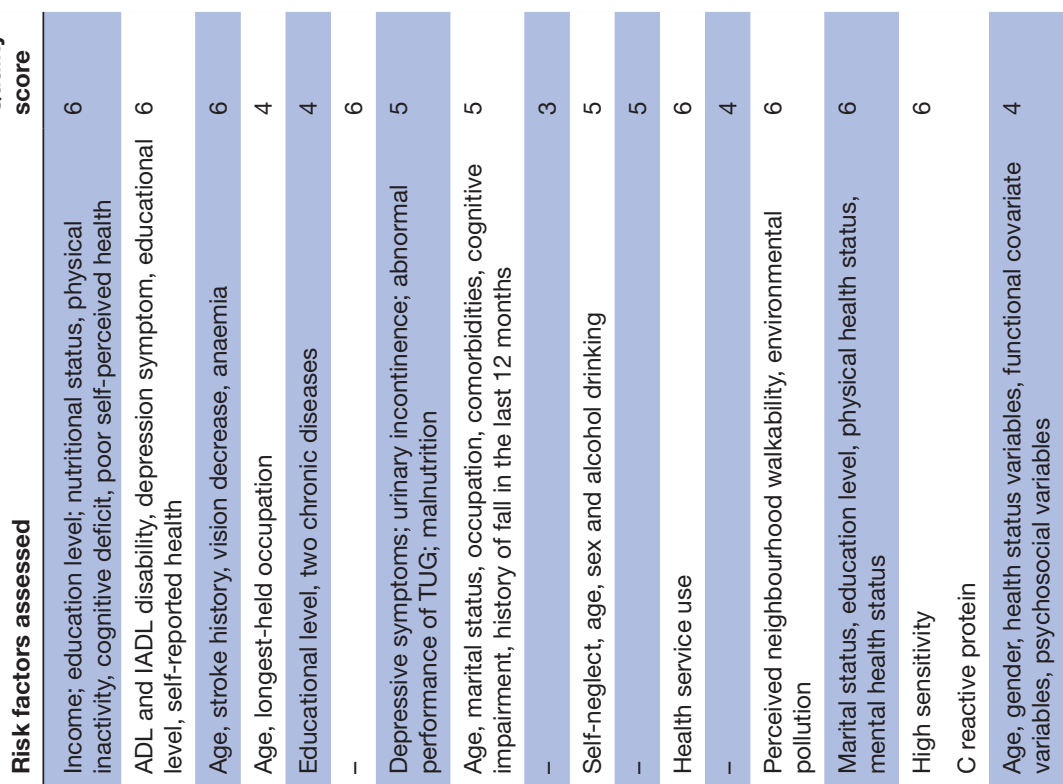

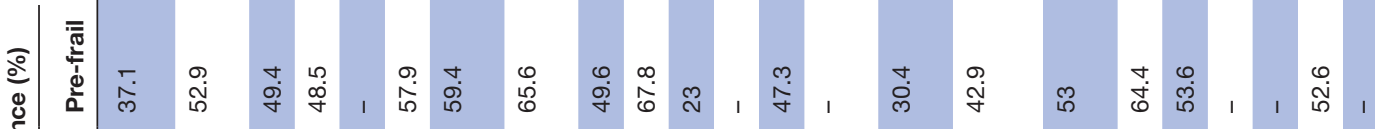

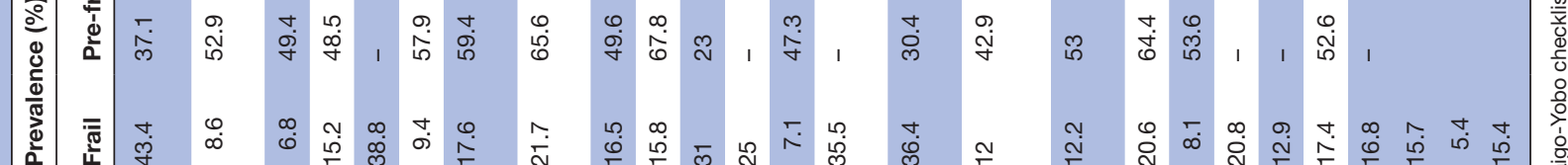

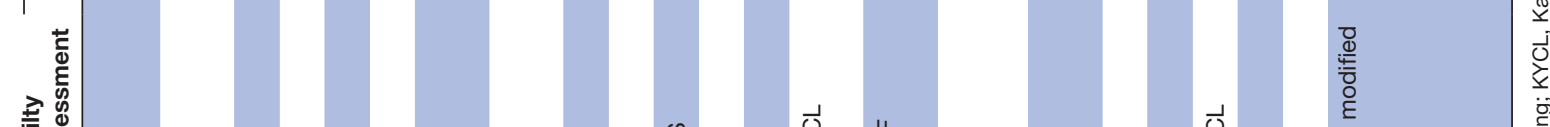

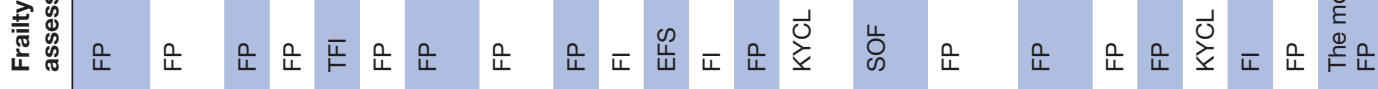

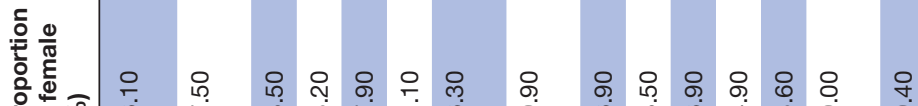

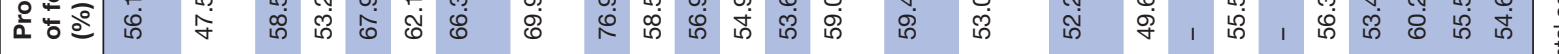

.

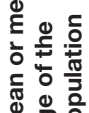

这

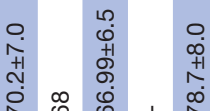

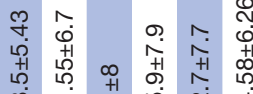

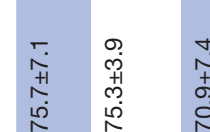

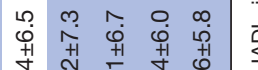

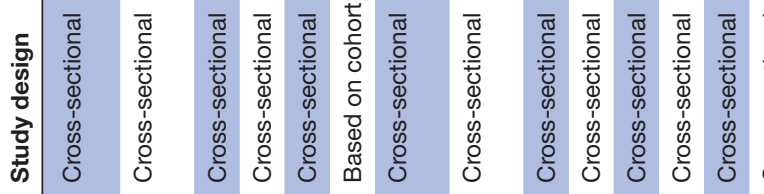

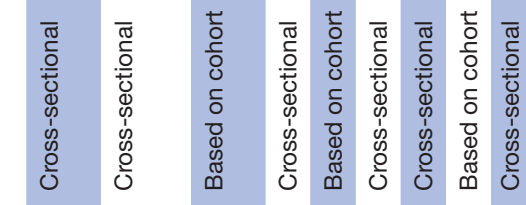

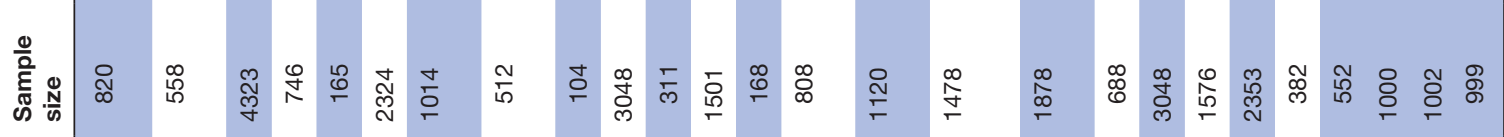




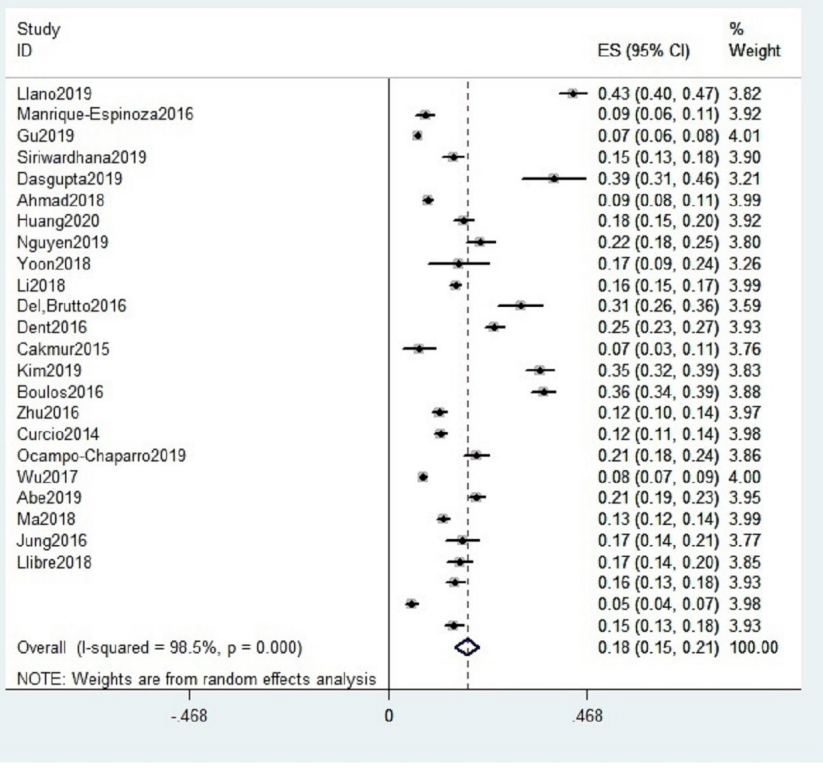

Figure 2 Forest plot of prevalence of frailty.

The pooled prevalence of frailty in rural elderly from this meta-analysis was $18 \%$ (95\% CI $15 \%$ to $21 \%$ ), higher than the global estimate $(10.7 \% ; 95 \%$ CI $10.5 \%$ to $10.9 \%$ ) which published in $2012 .{ }^{36}$ Differences in frailty prevalence estimates between rural areas and the global average may be due to the characteristics of studies included. Most of the people included in the global study came from cities and towns, however the participants of our meta-analysis came from the rural areas. Frailty was more common among rural areas, which may be explained by these reasons: (1) lower socioeconomic status among residents living in rural communities, (2) limited accessibility of healthcare services and resources, (3) relatively unhealthy lifestyle and limited healthcare awareness. ${ }^{19} 20$ Frailty has been proved to be associated with negative healthy outcomes, ${ }^{43} 38$ and studies from Canada, China and Korea found that frail rural elderly

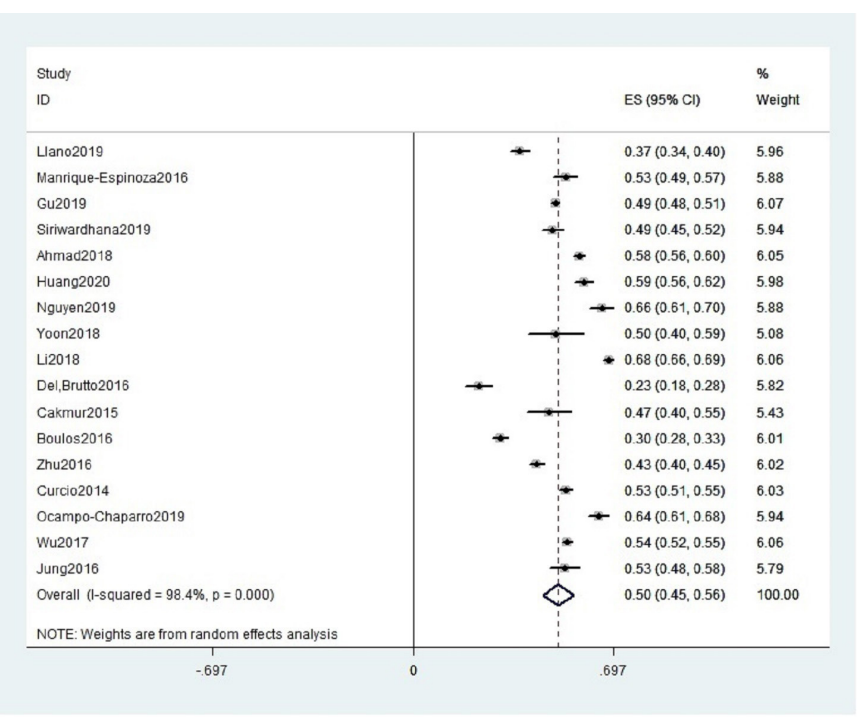

Figure 3 Forest plot of prevalence of pre-frailty.
Table 2 Subgroup analyses by frailty criteria, gender and level of development

\begin{tabular}{|c|c|c|c|c|}
\hline \multirow[b]{2}{*}{ Subgroups } & \multicolumn{4}{|l|}{ Frailty } \\
\hline & Prevalence (\%) & $95 \% \mathrm{Cl}$ & $I^{2}(\%)$ & $P$ value \\
\hline \multicolumn{5}{|l|}{ Frailty criteria } \\
\hline FP & 15 & $12 \%$ to $18 \%$ & 97.7 & $<0.001$ \\
\hline $\mathrm{FI}$ & 18 & $12 \%$ to $24 \%$ & 97.6 & $<0.001$ \\
\hline Other criteria & 32 & $24 \%$ to $40 \%$ & 96.4 & $<0.001$ \\
\hline \multicolumn{5}{|l|}{ Gender } \\
\hline Female & 26 & $20 \%$ to $31 \%$ & 98.4 & $<0.001$ \\
\hline Male & 17 & $13 \%$ to $22 \%$ & 97.4 & $<0.001$ \\
\hline \multicolumn{5}{|c|}{ Level of development } \\
\hline $\begin{array}{l}\text { Developing } \\
\text { countries }\end{array}$ & 17 & $14 \%$ to $20 \%$ & 98.4 & $<0.001$ \\
\hline $\begin{array}{l}\text { Developed } \\
\text { countries }\end{array}$ & 23 & $18 \%$ to $29 \%$ & 94.5 & $<0.001$ \\
\hline
\end{tabular}

FI, Frailty Index; FP, Fried phenotype.

have higher mortality than that in the city or town. ${ }^{39-41}$ Besides, in the context of the COVID-19 pandemic, study found that frailty can predict disease outcomes better in a large population of patients with COVID-19 than age or comorbidity and it is also meaningful to know the frailty of older people in rural areas. ${ }^{42}$ Hence, it is time to focus and improve the healthcare in rural areas, expect for improving the distribution of medical resources, strategies including support services, nutritional supplementation, exercise interventions and health education may also be useful to prevent and delay the occurrence and development of frailty. ${ }^{34}$ The pooled prevalence of prefrailty in this meta-analysis was found to be $50 \%$ (95\% CI $45 \%$ to $56 \%$ ). Pre-frailty is a transitional and potentially reversible risk state before the onset of frailty, and the fact that half of the rural elderly were pre-frail indicates that it is urgent to establish and implement early frailty prevention strategies among rural areas.

This analysis found that pooled prevalence of frailty varied based on the assessment tools used. In this

Table 3 Pooled risk factors of frailty

\begin{tabular}{llllcl}
\hline No. & Risk factors & OR & $\mathbf{9 5 \%} \mathbf{C l}$ & $\mathbf{I}^{\mathbf{2}}$ (\%) & P value \\
\hline 1 & Age & 1.05 & 1.03 to 1.08 & 0.0 & $<0.001$ \\
\hline 2 & $\begin{array}{l}\text { Cognitive } \\
\text { impairment }\end{array}$ & 1.97 & 1.41 to 2.54 & 0.0 & $<0.001$ \\
\hline 3 & $\begin{array}{l}\text { Depressive } \\
\text { symptom }\end{array}$ & 1.24 & 1.14 to 1.34 & 68.5 & $<0.001$ \\
\hline 4 & $\begin{array}{l}\text { Risk of } \\
\text { malnutrition }\end{array}$ & 2.49 & 1.51 to 3.48 & 62.0 & $<0.001$ \\
\hline 5 & $\begin{array}{l}\text { ADL disability } \\
6\end{array}$ & 2.59 & 1.71 to 3.48 & 0.0 & $<0.001$ \\
\hline $\begin{array}{l}\text { Poor self- } \\
\text { perception of } \\
\text { health }\end{array}$ & 2.42 & 1.39 to 3.45 & 0.0 & $<0.001$ \\
\hline
\end{tabular}

ADL, activity of daily living. 
meta-analysis, studies using the FP reported lower prevalence of frailty than those using the Frailty Index (FI) and other criteria, consistent with many other studies, ${ }^{14} 36$ and this suggests that researchers around the world recognised the definition of FP. The benefits of the FP include its relative ease of application, and another benefit is the minimal amount of data required for its calculation, making it a potential tool for screening. ${ }^{43}$ However, the FP has its roots in Canadian population surveys, and it is better to verify its applicability or to make an adjustment when used in other populations. The FI is another commonly used criterion, based on a deficit accumulation model,${ }^{44}$ and study found that the the electronic FI (eFI) overestimates the frailty status of communitydwelling older people compared with the Clinical Frailty Scale which is a validated measure of frailty based on clinical presentation. ${ }^{45}$ Hence, we need to consider carefully when using the FI and further work should also be conducted to identify a uniform scale that can be used to accurately identify frailty among populations.

Our stratified analysis of gender revealed that females were more likely to be frail than males among the older people in rural areas, which was consistent with previous reports. ${ }^{14} 36$ Females have a longer life expectancy, and this survival effects may result in a greater accumulation of frailty-associated deficits over time. ${ }^{46}$ Another possible explanation is that postmenopausal women have lower average amounts of lean body mass and muscle because of vitamin D deficiency, ${ }^{47}$ and the relationship between frailty and sarcopenia has been confirmed in previous research. $^{48}$

The result of our level of development-stratified analysis revealed that older people in rural areas from developed countries were more likely to be frail than older people from developing countries, and this is not consistent with another meta-analysis which found that the prevalence of frailty appeared higher in community-dwelling older adults in upper middle-income countries compared with high-income countries. ${ }^{49}$ This may be because older rural people in developed countries live longer than those in developing countries and further work should also be conducted to identify the differences in the incidence of frailty in countries at different levels of development.

The potential risk factors associated with frailty estimated in rural elderly were increasing age, cognitive impairment, depressive symptom, risk of malnutrition, ADL disability and poor self-perception of health. Ageing can be conceptualised as a deficit accumulation process of each physiological system, taking place in different individuals in different ways, with a variety of rates for different organ systems, making it necessary to find out prevalence and associated factors of different age groups of the elderly in rural areas. ${ }^{50}$ Limited data made it difficult to conduct a subgroup of age in this metaanalysis, but evidence from rural elderly in Sri Lanka had found the prevalence of frailty has almost doubled with the increasing of age (group: 75-79 years vs $\geq 80$ years; RR(Relative Risk): 4.07 vs 7.02). ${ }^{11}$ Park and $\mathrm{Yu}^{51}$ found that different age groups had different risk factors of frailty by analysing the data of 22868 elderly people, so targeted interventions for frailty prevention can reduce the pressure in rural areas with limited medical resources.

Cognitive impairment was associated with frailty in the rural elderly, consistent with results among the world that poor cognitive function is strongly closed associated with pre-frailty and frailty subgroups in older populations. ${ }^{52}$ Many factors are involved in the relationship between cognitive function and frailty, such as neuropathology, cardiovascular disease, inflammation, hormonal changes, nutrition, social isolation, social vulnerability and so on. ${ }^{53}$ As cognitive function contains several cognitive domains, it might be useful and necessary to determine which individual experienced cognitive deficits are most significantly associated with frailty scores.

Depression was associated with frailty among older people in rural areas, and this is due to that frailty and depression share the same pathophysiological mechanism. ${ }^{54}$ Besides, individuals with depressive symptoms usually have less physical activity, which will increase the probability of frailty. ${ }^{55}$ Risk of malnutrition was another risk factors associated with frailty, as weight loss, reduced intake of calorie and specific dietary pattern may change the body composition and physical function, which can increase the risk of frailty. ${ }^{55}$

ADL disability means the decreased ability of selfcare, affecting eating ability and physical activity, further causing malnutrition and muscle decline, eventually leading to frailty. ${ }^{56}$ Self-perception of health has been identified as a highly sensitive variable in elderly health estimations and a valid predictor of morbidity, ${ }^{9}$ and Jylhä et $a \bar{l}^{\tilde{7}}$ found self-appraisal has biological and cognitive underpinnings, existing as a predictor of frailty. Actually, rural older persons are exposed to a greater inequitable and precarious socioeconomic and health conditions throughout their life courses, and as a result, perception of the elderly regarding adverse experiences may predispose them to frailty.

The strength of this study is to focus on the frailty of elderly in rural areas that are easily neglected. However, there are still several limitations. The main limitation is the heterogeneity among studies. Moreover, the included articles mainly from Asia, South and North America, lacking studies from Europe and Africa, perhaps due to the difference in number and distribution of rural population. Third, the quality of the studies included was moderate, and we should be careful with research results.

\section{CONCLUSION}

The urban-rural gap is the main problem in the distribution of medical resources in various countries, and there are a large number of older people in rural areas who are the key populations to achieve equalisation of basic public health services. As a relatively neglected elderly group, a better insight of frailty and its risk factors will have widescale implications for healthcare policy and practice in 
rural-dwelling populations. This meta-analysis found that the pooled prevalence of frailty of older people was $18 \%$ in rural areas and many factors were associated with frailty, including age, cognitive impairment, depressive symptom, risk of malnutrition, ADL disability and poor self-perception of health. Hence, it is time to focus the frailty of older people in rural areas. In order to prevent and reduce the frailty of the older adults in rural areas, we can try to establish a frailty screening mechanism for the elderly in rural areas, pay attention to the key groups, and establish nutrition, exercise, diet and other interventions.

Contributors QL and MZ conceived and designed the study strategy; RX and FG completed the work of the article search, article assessment, data extraction, quality assessment and data analysis independently; LZ participated in the discussion when there was disagreement; RX wrote the manuscript. The definitive manuscript was read and approved by all authors.

Funding The authors have not declared a specific grant for this research from any funding agency in the public, commercial or not-for-profit sectors.

Competing interests None declared.

Patient consent for publication Not required.

Provenance and peer review Not commissioned; externally peer reviewed.

Data availability statement All data relevant to the study are included in the article or uploaded as supplemental information.

Supplemental material This content has been supplied by the author(s). It has not been vetted by BMJ Publishing Group Limited (BMJ) and may not have been peer-reviewed. Any opinions or recommendations discussed are solely those of the author(s) and are not endorsed by BMJ. BMJ disclaims all liability and responsibility arising from any reliance placed on the content. Where the content includes any translated material, BMJ does not warrant the accuracy and reliability of the translations (including but not limited to local regulations, clinical guidelines, terminology, drug names and drug dosages), and is not responsible for any error and/or omissions arising from translation and adaptation or otherwise.

Open access This is an open access article distributed in accordance with the Creative Commons Attribution Non Commercial (CC BY-NC 4.0) license, which permits others to distribute, remix, adapt, build upon this work non-commercially, and license their derivative works on different terms, provided the original work is properly cited, appropriate credit is given, any changes made indicated, and the use is non-commercial. See: http://creativecommons.org/licenses/by-nc/4.0/.

ORCID iD

Qiufang Li http://orcid.org/0000-0003-1788-5223

\section{REFERENCES}

1 Peel NM, McClure RJ, Bartlett HP. Behavioral determinants of healthy aging. Am J Prev Med 2005;28:298-304.

2 Strandberg TE, Pitkälä KH. Frailty in elderly people. Lancet 2007;369:1328-9.

3 Morley JE, Vellas B, van Kan GA, et al. Frailty consensus: a call to action. J Am Med Dir Assoc 2013;14:392-7.

4 Vermeiren S, Vella-Azzopardi R, Beckwée D, et al. Frailty and the prediction of negative health outcomes: a meta-analysis. J Am Med Dir Assoc 2016;17:1163.e1-e17.

5 Ahmad NS, Hairi NN, Said MA, et al. Prevalence, transitions and factors predicting transition between frailty states among rural community-dwelling older adults in Malaysia. PLoS One 2018;13:e0206445.

6 Sezgin D, Liew A, O'Donovan MR, et al. Pre-frailty as a multidimensional construct: a systematic review of definitions in the scientific literature. Geriatr Nurs 2020;41:139-46.

7 Chen ZG, Zhou YY, Fan SG. Rural revitalization from a global perspective. Issues in Agricultural Economy 2020:87-96.

8 Llano PMPde, Lange C, Sequeira CAdaC, et al. Factors associated with frailty syndrome in the rural elderly. Rev Bras Enferm 2019;72:14-21.

9 Manrique-Espinoza B, Salinas-Rodríguez A, Salgado de Snyder N, et al. Frailty and social vulnerability in Mexican deprived and rural settings. J Aging Health 2016;28:740-52.
$10 \mathrm{Gu}$ J, Chen $\mathrm{H}, \mathrm{Gu} \mathrm{X}$, et al. Frailty and associated risk factors in elderly people with health examination in rural areas of China. Iran $J$ Public Health 2019;48:1663-70.

11 Siriwardhana DD, Weerasinghe MC, Rait G, et al. Prevalence of frailty in rural community-dwelling older adults in Kegalle district of Sri Lanka: a population-based cross-sectional study. BMJ Open 2019;9:e026314.

12 Dasgupta A, Bandyopadhyay S, Bandyopadhyay L, et al. How frail are our elderly? An assessment with Tilburg frailty indicator (TFI) in a rural elderly population of West Bengal. J Family Med Prim Care 2019;8:2242-8.

13 Avila-Funes JA, Pelletier A, Meillon C, et al. Vascular cerebral damage in frail older adults: the AMImage study. J Gerontol A Biol Sci Med Sci 2017;72:971-7.

14 O'Caoimh R, Sezgin D, O'Donovan MR, et al. Prevalence of frailty in 62 countries across the world: a systematic review and metaanalysis of population-level studies. Age Ageing 2021;50:afaa219

15 Stroup DF, Berlin JA, Morton SC, et al. Meta-analysis of observational studies in epidemiology: a proposal for reporting. meta-analysis of observational studies in epidemiology (MOOSE) group. JAMA 2000;283:2008-12.

16 Fried LP, Tangen CM, Walston J, et al. Frailty in older adults: evidence for a phenotype. J Gerontol A Biol Sci Med Sci 2001;56:M146-57.

17 Loney PL, Chambers LW, Bennett KJ, et al. Critical appraisal of the health research literature: prevalence or incidence of a health problem. Chronic Dis Can 1998;19:170-6.

18 Isaacs AM, Riva-Cambrin J, Yavin D, et al. Age-specific global epidemiology of hydrocephalus: systematic review, metanalysis and global birth surveillance. PLoS One 2018;13:e0204926.

19 Huang C-Y, Lee W-J, Lin H-P, et al. Epidemiology of frailty and associated factors among older adults living in rural communities in Taiwan. Arch Gerontol Geriatr 2020;87:103986.

20 Nguyen AT, Nguyen LH, Nguyen TX, et al. Frailty prevalence and association with health-related quality of life impairment among rural community-dwelling older adults in Vietnam. Int J Environ Res Public Health 2019;16:3836.

21 Yoon DH, Hwang SS, Lee DW, et al. Physical frailty and cognitive functioning in Korea rural community-dwelling older adults. J Clin Med 2018;7:405

$22 \mathrm{Li} \mathrm{J}$, Zhao D, Dong B, et al. Frailty index and its associations with self-neglect, social support and sociodemographic characteristics among older adults in rural China. Geriatr Gerontol Int 2018;18:987-96.

23 Del Brutto OH, Mera RM, Sedler MJ, et al. The effect of age in the association between frailty and poor sleep quality: a populationbased study in Community-Dwellers (the Atahualpa project). J Am Med Dir Assoc 2016;17:269-71.

24 Dent E, Hoon E, Karnon J, et al. Frailty and health service use in rural South Australia. Arch Gerontol Geriatr 2016;62:53-8.

25 Çakmur H. Frailty among elderly adults in a rural area of Turkey. Med Sci Monit 2015;21:1232-42.

26 Kim M-J, Seo S-H, Seo A-R, et al. The association of perceived neighborhood Walkability and environmental pollution with frailty among community-dwelling older adults in Korean rural areas: a cross-sectional study. J Prev Med Public Health 2019;52:405-15.

27 Boulos C, Salameh P, Barberger-Gateau P. Malnutrition and frailty in community dwelling older adults living in a rural setting. Clin Nutr 2016;35:138-43.

28 Zhu Y, Liu Z, Wang Y, et al. C-reactive protein, frailty and overnight hospital admission in elderly individuals: a population-based study. Arch Gerontol Geriatr 2016;64:1-5.

29 Curcio C-L, Henao G-M, Gomez F. Frailty among rural elderly adults. BMC Geriatr 2014;14:2.

30 Ocampo-Chaparro JM, Reyes-Ortiz CA, Castro-Flórez X, et al. Frailty in older adults and their association with social determinants of health. The SABE Colombia study. Colomb Med 2019;50:89-101.

31 Wu C, Smit E, Xue Q-L, et al. Prevalence and correlates of frailty among community-dwelling Chinese older adults: the China health and retirement longitudinal study. J Gerontol 2018;73:102-8.

32 Abe T, Kitamura A, Seino S, et al. Differences in the prevalence of and factors associated with frailty in five Japanese residential areas. Int J Environ Res Public Health 2019;16:3974.

33 Ma L, Tang Z, Zhang L, et al. Prevalence of frailty and associated factors in the community-dwelling population of China. J Am Geriatr Soc 2018;66:559-64.

34 Jung $\mathrm{H}-\mathrm{W}$, Jang I-Y, Lee YS, et al. Prevalence of frailty and agingrelated health conditions in older Koreans in rural communities: a cross-sectional analysis of the aging study of Pyeongchang rural area. J Korean Med Sci 2016;31:345-52. 
35 Llibre Rodriguez JJ, Prina AM, Acosta D, et al. The prevalence and correlates of frailty in urban and rural populations in Latin America, China, and India: a 10/66 population-based survey. J Am Med Dir Assoc 2018;19:287-95.

36 Collard RM, Boter H, Schoevers RA, et al. Prevalence of frailty in community-dwelling older persons: a systematic review. J Am Geriatr Soc 2012;60:1487-92.

37 Hewitt J, Carter B, McCarthy K, et al. Frailty predicts mortality in all emergency surgical admissions regardless of age. An observational study. Age Ageing 2019;48:388-94.

38 Hewitt J, Long S, Carter B, et al. The prevalence of frailty and its association with clinical outcomes in general surgery: a systematic review and meta-analysis. Age Ageing 2018;47:793-800.

39 Song X, MacKnight C, Latta R, et al. Frailty and survival of rural and urban seniors: results from the Canadian study of health and aging. Aging Clin Exp Res 2007;19:145-53.

40 Yu P, Song X, Shi J, et al. Frailty and survival of older Chinese adults in urban and rural areas: results from the Beijing longitudinal study of aging. Arch Gerontol Geriatr 2012;54:3-8.

41 Jang I-Y, Jung H-W, Lee CK, et al. Rural and urban disparities in frailty and aging-related health conditions in Korea. J Am Geriatr Soc 2016;64:908-11.

42 Hewitt J, Carter B, Vilches-Moraga A, et al. The effect of frailty on survival in patients with COVID-19 (COPE): a multicentre, European, observational cohort study. Lancet Public Health 2020;5:e444-51.

43 Lewis EG, Coles S, Howorth K, et al. The prevalence and characteristics of frailty by frailty phenotype in rural Tanzania. BMC Geriatr 2018;18:283

44 Rockwood K, Mitnitski A. Frailty in relation to the accumulation of deficits. J Gerontol A Biol Sci Med Sci 2007;62:722-7.

45 Broad A, Carter B, Mckelvie S, et al. The convergent validity of the electronic frailty index (eFI) with the clinical frailty scale (CFS) Geriatrics 2020;5:88.
46 Gordon EH, Peel NM, Samanta M, et al. Sex differences in frailty: a systematic review and meta-analysis. Exp Gerontol 2017;89:30-40.

47 Venning G. Recent developments in vitamin D deficiency and muscle weakness among elderly people. BMJ 2005;330:524-6.

48 Morley JE, Malmstrom TK, Rodriguez-Mañas L, et al. Frailty, sarcopenia and diabetes. J Am Med Dir Assoc 2014;15:853-9.

49 Siriwardhana DD, Hardoon S, Rait G, et al. Prevalence of frailty and prefrailty among community-dwelling older adults in low-income and middle-income countries: a systematic review and meta-analysis. BMJ Open 2018;8:e018195.

50 Fulop T, Larbi A, Witkowski JM, et al. Aging, frailty and age-related diseases. Biogerontology 2010;11:547-63.

51 Park E, Yu M. Frailty and its related factors in vulnerable elderly population by age groups. J Korean Acad Nurs 2016;46:848-57.

52 Furtado GE, Caldo A, Rieping T, et al. Physical frailty and cognitive status over-60 age populations: a systematic review with metaanalysis. Arch Gerontol Geriatr 2018;78:240-8.

53 Yun J-H, Ki S-K, Kim J, et al. Relationships between cognitive function and frailty in older Korean adults: the moderating effect of the number of teeth. Arch Gerontol Geriatr 2020;91:104213.

54 Kwan RYC, Leung AYM, Yee A, et al. Cognitive frailty and its association with nutrition and depression in community-dwelling older people. J Nutr Health Aging 2019;23:943-8.

55 Cruz-Jentoft AJ, Kiesswetter E, Drey M, et al. Nutrition, frailty, and sarcopenia. Aging Clin Exp Res 2017;29:43-8.

56 Perna S, Francis M, Bologna C, et al. Performance of Edmonton frail scale on frailty assessment: its association with multi-dimensional geriatric conditions assessed with specific screening tools. BMC Geriatr 2017;17:2.

57 Jylhä M, Volpato S, Guralnik JM. Self-rated health showed a graded association with frequently used biomarkers in a large population sample. J Clin Epidemiol 2006;59:465-71. 